\title{
Comparison of Modified Kessler Technique versus Four Strand Cruciate Technique for Repair of Long Flexor Tendons of Fingers: A Randomized Controlled Trial
}

\author{
Safdar Ali Shaikh ${ }^{1}$, Amber Bawa ${ }^{1}$, Noman Shahzad ${ }^{2 *}$, Sobia Yasmeen ${ }^{1}$, Mirza Shehab Afzal Beg \\ ${ }^{1}$ Department of Plastic Surgery, Liaquat National Hospital Karachi, Pakistan \\ ${ }^{2}$ Department of Surgery, Aga Khan University Hospital Karachi, Pakistan \\ *Corresponding author: Noman Shahzad, Department of Surgery, Aga Khan University Hospital Karachi, Pakistan \\ Submission: March 26, 2018; Published: April 12, 2018
}

\begin{abstract}
Introduction: : Hand Tendon injuries are not uncommon. Achieving a satisfactory range of motion and preventing tendon rupture after repair of flexor tendon injuries remains a challenge to hand surgeons..
\end{abstract}

Objectives: To compare functional outcome of tendon repair with Modified Kessler and four strand cruciate techniques.

Material and Methods: Randomized control trial was conducted from July 2013 to June 2015. Both male and female patients of age 18 to 60 years who had clean lacerated injury proximal to wrist crease (Zone V) were eligible for inclusion in the study. Patients with dirty or infected wounds, or those having multiple injuries other than tendons, having injury to extensor tendons were excluded from the study. Arm A comprised of patients who underwent modified Kessler repair and Arm B included patients whose repair was done via four strand cruciate repair technique. The final outcome at 8 weeks was compared by using Strickland's evaluation system.

Results: A total of 140 fingers of 44 patients with sharp wrist laceration injury of long flexor tendons of fingers were included in this study. The average age of patients was $28.05 \pm 10.42$ years. Out of 44 patients, $28(63.64 \%)$ were males and $16(36.36 \%)$ females. At 8th week, satisfactory functional outcome (excellent group according to Strickland evaluation) was observed in $65.7 \%(46 / 70)$ fingers in four strand cruciate repair technique and in $28.6 \%$ (20/70) fingers in standard modified Kessler repair technique and the difference was statistically significant $(\mathrm{P}<0.001)$.

Conclusion: Four strand cruciate repair technique is better than standard modified Kessler method for repair of long flexor tendons of fingers.

Keywords: Impairments; Activity limitations; Green houses; Senior living; Outcome measure

\section{Introduction}

Hand injuries have become one of the commonest reasons for patients to visit emergency departments of hospitals [1]. Sharp injuries leading to flexor tendon tears have always remained a challenge for doctors to bring the patients back to normal condition and saving them from prolonged disability and emotional suffering [2]. Though primary repair of such tendons injuries is the standard of treatment but repairs are not free of complications [3]. After the repair of flexor tendons achieving good range of motion is challenge while avoiding disruption of repair [3]. In initial phase after the repair, it is the technique that underlies the strength of repair. This is why various methods and techniques of tendon repair have been reported ranging from double strand to multiple strand core sutures and with various suture materials $[4,5]$. Though the increasing number of core sutures have shown increased gap resistance and fatigue strength, modified Kessler 2 strand repair still is the most commonly applied technique for many years $[2,6]$.

Early mobilization after repair is known to prevent contractures $[6,7]$. By increasing number of core sutures in repair of flexor tendons one can perform early active and passive physiotherapy, which may help in resuming normal function earlier and better than standard modified Kessler repair technique.

Objective of this randomized controlled trial was to compare functional outcome of tendon repair with Modified Kessler as compared to four strand cruciate technique. Schematic diagrams of both repairs are as shown in Figure 1. 


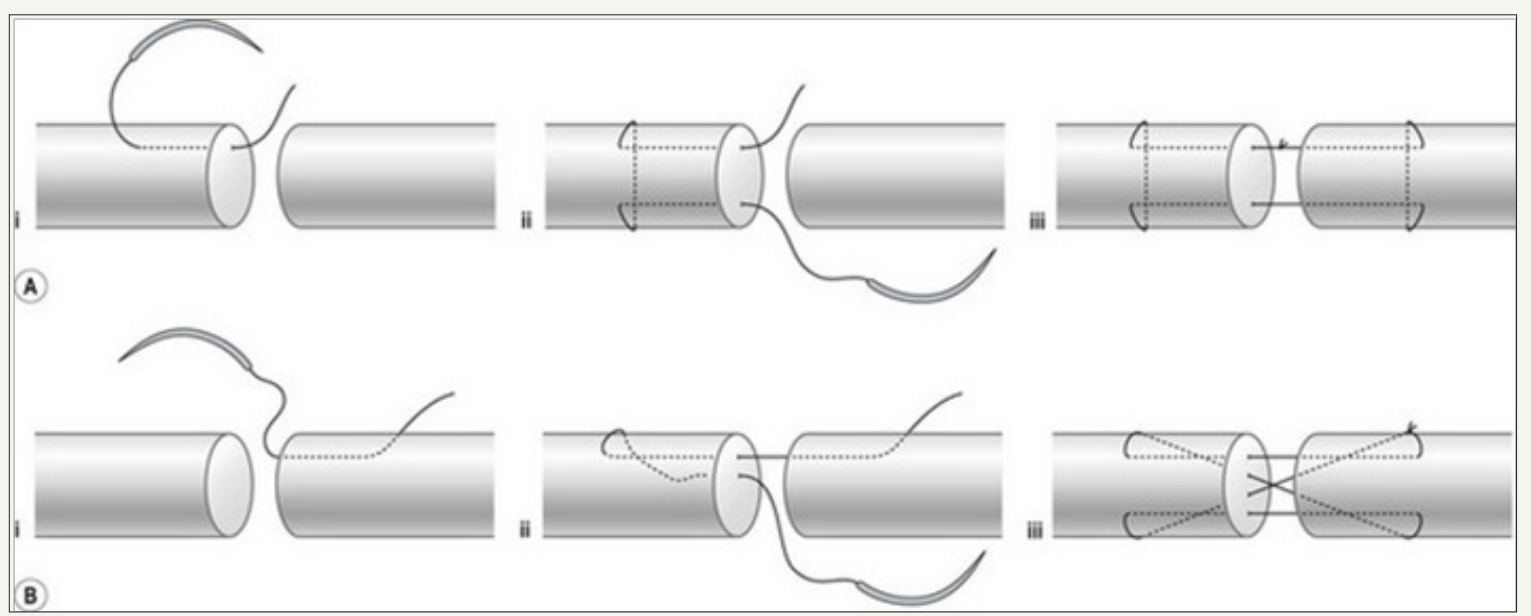

Figure 1: (A) Modified Kessler repair, (B) For Strand Cruciate Repair.

\section{Materials and Methods}

We conducted a randomized control trial in the department of Plastic Surgery, Liaquat National Hospital Karachi from July 2013 to June 2015. Non probability consecutive sampling technique was used for patients selection. Both male and female patients of age 18 to 60 years who had clean lacerated injury proximal to wrist crease (Zone V) were eligible for inclusion in the study. Patients with dirty or infected wounds, or those having multiple injuries other than tendons, having injury to extensor tendons were excluded from the study. To each eligible patient, procedure was explained by principal investigator and informed written consent for participation in the trial was taken. Participants were assigned to the two arms based upon technique of repair. Arm A comprised of patients who underwent modified Kessler repair and Arm B included patients whose repair was done via four strand cruciate repair technique. Allocation was done using random number table. All operations were performed by consultant plastic surgeons. Each method was followed by repair of epitenon with continuous running sutures. Postoperatively patients of both arms were rehabilitated by Belfast technique which includes dorsal blocking splint for 6 weeks with early active and passive mobilization. All Patients were evaluated postoperatively at 2 weeks, 4 weeks, 6 weeks and 8 weeks for assessment of total active motion.

The final outcome of the two techniques was compared by using Strickland's evaluation system as given in the following equation. Strickland $=\frac{(\text { activeflexionPIP }+D I P)-(\text { extensiondeficitPIP }+D I P)}{175^{\circ}} \times 100 \%$

Excellent: (85-100\%), Good: (70-84\%), Fair: (50-69\%), Poor: $(<50 \%)$

Outcome on 8 weeks was considered as the final Outcome. It was labeled as Satisfactory (excellent group), Fair (good and fair groups) and Poor (poor group) according to Strickland's evaluation system.

Data collection was done after approval of ethical review board of hospital.

\section{Data Analysis}

Data was entered and analyzed with SPSS version 19.0. The qualitative variables i.e. gender, hand dominance, and final outcome category (i.e. satisfactory, fair and poor) are presented as frequencies and percentages in both groups. Quantitative variables like age is presented as mean $\pm \mathrm{SD}$. Chi square test was used to compare the final outcome in both the groups. $\mathrm{P}$ value $\leq 0.05$ was take as statistically significant.

\section{Results}

A total of 140 fingers (70 in each arm) of 44 patients with sharp wrist laceration injury of long flexor tendons of fingers were included in this study. The average age of patients was $28.05 \pm$ 10.42 years. Median number of fingers affected per patient were 3 (IQR: 1-5). Out of 44 patients, 28 (63.64\%) were males and 16 (36.36\%) females. Regarding the hand dominance of the patients, $16(36.36 \%)$ had injury to dominant hand and 28 (63.64\%) had injury to non-dominant hand. Similarly out of 140 injured fingers, $5.7 \%$ (8/140) were thumbs, $17.1 \%$ (24/140) index fingers, $31.4 \%$ (44/140) middle fingers, 30\% (42/140) ring fingers and $15.7 \%$ $(22 / 140)$ were little fingers. At 8 th week, satisfactory functional outcome (excellent group according to Strickland evaluation) was observed in $65.7 \%(46 / 70)$ fingers in four strand cruciate repair technique and in 28.6\% (20/70) fingers in standard modified Kessler repair technique and the difference was statistically significant $(\mathrm{P}<0.001)$. Results are as shown in Table 1.

Table 1: Functional outcome of tendons of fingers at 8 weeks.

\begin{tabular}{|c|c|c|c|}
\hline Final Outcome & $\begin{array}{c}\text { Modified KESS- } \\
\text { LER N=70 }\end{array}$ & $\begin{array}{c}\text { Four Strand } \\
\text { Cruciate N=70 }\end{array}$ & \multirow{2}{*}{ P Value } \\
\hline Satisfactory & $20(28.6 \%)$ & $46(65.7 \%)$ & \\
\hline Fair & $50(71.4 \%)$ & $24(34.3 \%)$ & \\
\hline
\end{tabular}




\section{Discussion}

Each specific movement of the hand relies on the finely tuned biomechanical interplay of the intrinsic and extrinsic musculotendinous forces. Restoring digital function after a flexor tendon injury continues to be one of the greatest challenges in the field of hand surgery [8]. Advances in understanding of tendon anatomy, nutrition, healing, and postoperative rehabilitation have generated an evolution of techniques that have enhanced the results of flexor tendon repair [9].

The technique of surgical repair for zone two flexor tendon injuries has been debated extensively through the years but adhesion formation, suture rupture, and suture locking on the pulley edge remain possible consequences of a poor repair [10]. Although increasing the repair strength through increasing the number of strands crossing the repair site to allow active postoperative mobilization without increasing the risk of rupture is logical, it can compromise tendon gliding function. Furthermore, increased numbers of strands increase the tendon bulk and surface irregularity which has mechanical implications on gliding function [11].

The in vitro benefits of multi-strand suture techniques are not necessarily reflected in improved results in vivo. Several studies have shown that multi-strand techniques may have a higher gliding resistance in vitro [12-14]. Zhao et al. [15] compared adhesion formation in two-strand modified Kessler and four-strand Becker repairs in a canine model. These techniques were chosen because they had relatively low (Kessler) and high (Becker) gliding resistances and both groups underwent a passive postoperative mobilization programme. The Kessler group was found to require significantly less force to break adhesions at 3 and 6 weeks after repair, leading the authors to conclude that gliding resistance may be more important than suture strength, provided a low-force passive gliding postoperative programme is used. However, Strick et al. [16] showed that adhesion formation and gliding resistance of tendons repaired with a two strand or four-strand modified Kessler core suture in a chicken model was not significantly different, which suggests that simply increasing the number of strands crossing a repair does not necessarily result in more adhesions or resistance.

It is well accepted that core-suture techniques using a greater number of suture strands across the repair site result in a greater tensile strength than those with a similar pattern but fewer sutures across the repair site [17-19]. Numerous studies performed on in vitro models involving commonly used core suture techniques have demonstrated the superiority of the four-strand core suture over the two-strand core suture. In an in vitro model, Thurman et al. [20] found that the 2-strand repair had significantly greater gap formation after cyclic loading (mean gap, $2.75 \mathrm{~mm}$ ) than either the 4-strand $(0.30 \mathrm{~mm})$ or 6 - strand $(0.31 \mathrm{~mm})$ repair. The tensile strength of the 6- strand repair (mean, $78.1 \mathrm{~N}$ ) was significantly greater than either the 4-strand (means, $43.0 \mathrm{~N}$ ) or 2-strand (mean, $33.9 \mathrm{~N}$ ) repair. Barrie et al. [21] in a biomechanical study using an in situ testing model demonstrated multi-strand repairs have greater tensile strength and gap resistance than 2-strand repair techniques.

\section{Conclusion}

Four strand cruciate repair technique is better than standard modified Kessler method for repair of long flexor tendons of fingers.

\section{References}

1. Yuen MH, lp WY (2007) Tensile strength of modified 4-strand cruciate technique for transversely or obliquely lacerated tendons. J Orthop Surg 15(1): 27-31.

2. Ahmad M, Hussain SS, Tariq F, Rafiq Z, Khan MA, et al. (2007) Flexor tendon injuries of hand: Experience at Pakistan institute of medical sciences, Islamabad, Pakistan. J Ayub Med Coll 19(1): 6-9.

3. Navali AM, Rouhani A (2008) Zone 2 Flexor Tendon Repair In Young Children: A Comparative Study of Four-Strand Versus Two-Strand Repair. J Hand Surg 33(4): 424-429.

4. Wu FY, Cao Y, Zhou YL, Tang JB (2011) Biomechanical comparisons of four-strand tendon repairs with double-stranded sutures: Effects of different locks and suture geometry. J Hand Surg 36(1): 34-39.

5. Viinikainen A, Göransson H, Ryhänen J (2008) Primary flexor tendon repair techniques. Scandinavian J Surg (97): 333-340.

6. Griffin M, Hindocha S, Jordan S, Saleh M, Khan W (2012) An Overview of the Management of Flexor Tendon Injuries. The Open Ortho J 6: 28-35.

7. Navali AM, Rouhani AR, Mortazavi MJ (2008) A comparative study of two suture configurations in zone II flexor tendon repair in adults. Acta Medica Iranica 46(3): 207-212.

8. Neumeister M, Wilhemi BJ, Bueno RA (2006) Flexor tendon lacerations.

9. Taras JS, Hunter JM (1994) Acute tendon injuries. In: Cohen M (Eds.), Mastery of Plastic and Reconstructive Surgery. New York: Little Brown and Co., USA pp. 550-556.

10. Zobitz ME, Zhao C, Amadio PC, An KN (2000) Comparison of mechanical properties of various suture repair techniques in a partially lacerated tendon. J Biomech Eng 122(6): 604-607.

11.Su BW, Solomons M, Barrow A, Senoge ME, Gilberti M, et al. (2005) Device for zone-II flexor tendon repair. A multicenter, randomized, blinded, clinical trial. J Bone Joint Surg Am 87(5): 923-935.

12. Galanakis I, Aligizakis A, Katonis P, Vavouranakis H, Stergiopoulos K, et al. (2003) Functional evaluation after primary flexor tendon repair in Zone II. Acta Orth Belg 69(3): 252-256.

13. Momose T, Amadio PC, Zhao C, Zobitz ME, Couvreur PJ (2001) Suture techniques with high breaking strength and low gliding resistance: experiments in the dog flexor digitorum profundus tendon. Acta Orthopaedica Scandinavica 72: 635-641.

14. Sanders DW, Milne AD, Johnson JA, Dunning CE, Richards RS (2001) The effects of flexor tendon repair bulk on tendon gliding during simulated active motive motion: an in vitro comparison of two-strand and sixstrand techniques. J Hand Surgery 26A: 833-880.

15. Zhao C, Amadio PC, Momose T, Couvreur P, Zobitz ME, et al. (2002) Effect of synergistic wrist motion on adhesion formation after repair of partial flexor digitorum profundus tendon lacerations in a canine model in vivo. J Bone and Joint Surg 84A: 78-84.

16. Strick MJ, Filan SL, Hile M, McKenzie C (2004) Adhesion formation after flexor tendon repair: a histologic and biomechanical comparison of 2and 4-strand repairs in a chicken model. J Hand Surgery 29(1): 15-22. 
17. Dinopoulos HT, Boyer MI, Burns ME, Gelberman RH, Silva MJ (2000) The resistance of a four- and eight-strand suture technique to gap formation during tensile testing: an experimental study of repaired canine flexor tendons after 10 days of in vivo healing. J Hand Surg 25(3): 489-498.

18. Winters SC, Seiler JG, Woo SL, Gelberman RH (1997) Suture methods for flexor tendon repair. A biomechanical analysis during the first six weeks following repair. Ann Chir Main Memb Super 16(3): 229-234.

19. Winters SC, Gelberman RH, Woo SL, Chan SS, Grewal R, et al. (1998) The effects of multiple-strand suture methods on the strength and excursion of repaired intrasynovial flexor tendons: a biomechanical study in dogs. J Hand Surg 23(1): 97-104.
20. Thurman RT, Trumble TE, Hanel DP, Tencer AF, Kiser PK (1998) Two-, four-, and six-strand zone II flexor tendon repairs: an in situ biomechanical comparison using a cadaver model. J Hand Surg 23(2): 261-265.

21. Barrie KA, Wolfe SW, Shean C, Shenbagamurthi D, Slade JF, et al. (2000) A biomechanical comparison of multistrand flexor tendon repairs using an in situ testing model. J Hand Surg 25(3): 499-506.
Creative Commons Attribution 4.0 International License

For possible submissions Click Here

\section{Submit Article}

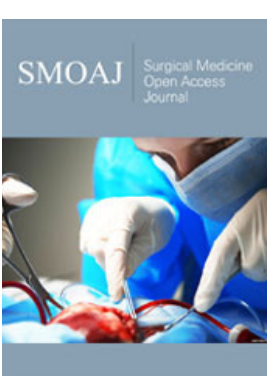

\section{Surgical Medicine Open Access Journal}

\section{Benefits of Publishing with us}

- High-level peer review and editorial services

- Freely accessible online immediately upon publication

- Authors retain the copyright to their work

- Licensing it under a Creative Commons license

- Visibility through different online platforms 